\title{
Assessing Bioequivalence of Antiepileptic Drugs: Are the Current Requirements too Permissive?
}

\author{
Camila F Rediguieri ${ }^{1,2}$ and Jorge L Zeredo ${ }^{3}$ \\ ${ }^{1}$ Department of Bioequivalence, General Office of Medicines, Brazilian National Health Surveillance Agency (ANVISA), \\ SIA Trecho 5 AE 57, Brasilia - DF, Brazil. ${ }^{2}$ Fundação Oswaldo Cruz, Av. L3 Norte, Campus Universitários Darcy Ribeiro, \\ Gleba A, SC 10, Brasília - DF, Brazil. ${ }^{3}$ University of Brasilia, Centro Metropolitano Conjunto A Lote 01, Brasília - DF, \\ Brazil.
}

Received, December 9, 2013; Revised, April 22, 2014; Accepted, May 11, 2014; Published, May 12, 2014.

\begin{abstract}
Purpose: In order to evaluate the permissiveness of current bioequivalence requirements for antiepileptic drugs we investigated how accurate $\mathrm{C}_{\max }$ and $\mathrm{AUC}_{0-\mathrm{t}}$ of generic antiepileptic drugs approved in Brazil are in comparison to reference products. Methods: Data collected from assessment reports of approved bioequivalence studies archived in the Brazilian regulatory agency in 2007-2012 were: geometric mean ratios and $90 \%$ confidence intervals $(\mathrm{CI})$ for $\mathrm{C}_{\max }$ and $\mathrm{AUC}_{0-\mathrm{t}}$, intra-subject variability $(\mathrm{CV})$ of $\mathrm{C}_{\max }$ and $\mathrm{AUC}_{0-\mathrm{t}}$ and number of subjects. Results: The average difference in $\mathrm{C}_{\max }$ and $\mathrm{AUC}_{0-\mathrm{t}}$ between generic and reference products was $5 \%$ and $3 \%$, respectively. Maximum deviation from 1.00 of the $\mathrm{CI}$ of $\mathrm{C}_{\max }$ can achieve $15-20 \%$ (demonstrated in $27 \%$ of studies); for $\mathrm{AUC}_{0-\mathrm{t}}, 25 \%$ of studies showed the deviation can be $>10 \%$. All studies that used adequate number of subjects for a $90 \%$ CI of $0.90-1.11$ complied with it for $\mathrm{AUC}_{0-\mathrm{t}}$, except one of carbamazepine, but only $33 \%$ complied with it for both $\mathrm{AUC}_{0-\mathrm{t}}$ and $\mathrm{C}_{\max }$. The $\mathrm{CV}$ was strongly correlated to the maximum $\mathrm{CI}$ deviation for $\mathrm{AUC}_{0-\mathrm{t}}(\mathrm{CV}$ of approximately $15 \%$ corresponding to deviation of $10 \%)$. Studies that presented maximum CI deviation $\leq 10 \%$ together with $\mathrm{CV} \leq 15 \%$ for $\mathrm{AUC}_{0-\mathrm{t}}$ represented $65 \%$ of the total. Weaker correlation was observed for $\mathrm{C}_{\max }$ and no correlation was seen between maximum $\mathrm{CI}$ deviation and number of subjects. Conclusions: Modification in legislation for bioequivalence of antiepileptic drugs is suggested, not only with constraint of $\mathrm{AUC}_{0-\mathrm{t}} 90 \% \mathrm{CI}$ to $0.90-1.11$, but also with limitation of the $\mathrm{CV}$ to $15 \%$, as to assure similar variance in pharmacokinetics and diminish the risk of critical plasma-level fluctuation when switching between generic and reference formulations. Although most generics presented differences $\leq 10 \%$ in $\mathrm{AUC}_{0-\mathrm{t}}$ compared to their references, some narrow therapeutic index drugs displayed differences that could be clinically significant after product substitution.
\end{abstract}

This article is open to POST-PUBLICATION REVIEW. Registered readers (see "For Readers") may comment by clicking on ABSTRACT on the issue's contents page.

\section{INTRODUCTION}

Pharmacotherapy is the first option of treatment in most epilepsy cases. Almost $70 \%$ of the patients rely on the use of antiepileptic drugs (AEDs) (1); therefore the financial burden of a life-time medication is a matter of concern. Although the price of the innovator is usually much higher than that of the generic product $(2,3)$, the substitution of the brand name product has been subject of debate over the past 20 years (4). In addition, AED products may need to be substituted for other reasons, such as commercial accessibility or availability in the public health service. The critical issue about epilepsy is that a single breakthrough seizure for a seizure-free patient will destroy what he or she may have gained over many years: independent living capabilities, self-confidence, driving license, good employment, loss of stigmatization; and will put he or she in risk of injury, hospitalization and death (5).

To receive marketing authorization, generic medicines need to have comparable bioavailability to the reference product demonstrated through bioequivalence (BE) studies. Test and reference products are considered bioequivalent if the limits of the $90 \%$ confidence interval (CI) of the geometric mean ratios (GMRs) of the pharmacokinetic (PK) parameters peak plasma concentration $\left(\mathrm{C}_{\max }\right)$ and area under the plasma concentration versus time curve (AUC) are $\geq 0.80$ and $\leq 1.25(6-8)$.

Corresponding Author: Camila F Rediguieri, Department of Bioequivalence, General Office of Medicines, Brazilian National Health Surveillance Agency (ANVISA), SIA Trecho 5, Brasília - DF, Brazil. Email: camila.rediguieri@anvisa.gov.br 
Two one-sided tests are used to analyze the PK parameter data (9). One test certifies that the PK parameters of the generic product are not more than $20 \%$ less than that of the reference product. The second test verifies that the PK parameters of the reference product are not more than $20 \%$ less than that of generic product. The $20 \%$ criteria was based on the experience of the United States Food and Drug Administration (FDA) medical experts who supported that a $\pm 20 \%$ difference in blood concentrations would not be clinically relevant (10). Thus the ratios test/reference and reference/test have to be not less than 0.8. The upper limit of the CI reaches up to 1.25 because, by convention, all data are expressed as test/reference ratios and the reciprocal of 0.8 is 1.25 .

For AEDs, however, many neurologists and researchers worry that the BE CI limits are not small enough to keep control of the seizures and adverse effects $(2,5,11,12)$. In addition, the traditional average BE approach does not guarantee that in all individuals the response of the generic product will be $\geq 0.80$ and $\leq 1.25$ times that of the innovator response. If a drug product produces variable responses within a subject, known as intra-subject variability, it is merely a matter of enrolling more subjects in the study to make the CI meet the adequate boundaries.

A number of studies have reported that the rates of generics to references switchbacks are about 3 to 4-fold higher for AEDs than for non-AEDs (13-15) and that seizure episodes and adverse effects increased after reference product substitution $(2,5$, $11,12,16,17)$. While it is possible that a number of other factors may have played a role in those outcomes, it nevertheless incites concern among patients, prescribing doctors and the public health service toward product substitution in epilepsy treatment. In a survey carried out in Brazil, nearly $57 \%$ of epilepsy patients who switched AED formulations complained of increased number of seizures after the change and nearly $48 \%$ reported increased side effects (18). Although the percentage of seizures in the patients who did not change the formulations was not reported, such high values raised interest on the performance of AED products approved by the Brazilian Health Surveillance Agency (ANVISA). In this study we assessed the accuracy of generic AED products in comparison to their respective reference products based on the results of BE studies approved by ANVISA. Subsequently, we proposed further constraints to the current requirements for bioequivalence of $\mathrm{AED}$

\section{ABBREVIATIONS}

AED - Antiepileptic Drug

ANVISA - Brazilian Health Surveillance Agency

AUC - Area under the plasma concentration versus time curve

$\mathrm{AUC}_{0-\mathrm{t}}-\mathrm{AUC}$ until the last sampling time $\mathrm{t}$

$\mathrm{BE}$ - Bioequivalence

CI - Confidence Interval

$\mathrm{C}_{\max }$ - Maximum plasma concentration

$\mathrm{CV}$ - Intra-subject variability or Coefficient of

variation

FDA - Food and Drug Administration

GMR - Geometric mean ratio

PK - Pharmacokinetics

products, taking in consideration the pharmacological characteristics of those drugs.

\section{METHODS}

\section{Bioequivalence study selection and assessed data}

BE studies were selected from a database maintained by the Bioequivalence Department of ANVISA. Rejected BE studies were excluded. For convenience, only studies with statistical assessment reports archived in the electronic database were selected (i.e., from 2007 to 2012).

Data assessed were $\mathrm{C}_{\max }$ and $\mathrm{AUC}_{0-\mathrm{t}}$ (AUC until the last sampling time t) GMRs and 90\% CIs, intrasubject variability or coefficient of variation $(\mathrm{CV})$ for $\mathrm{C}_{\max }$ and $\mathrm{AUC}_{0-\mathrm{t}}$ and number of subjects who completed the studies. Demographic data available were gender and health conditions (healthy subjects or patients). The ethnicity data were not available, only the countries where the clinical phases were conducted.

\section{Bioequivalence evaluation}

GMRs were taken from ANVISA's assessment reports and tabulated. The range of GMRs values was indicated. The absolute differences between the test and reference were calculated by subtracting the GMRs from 1.00, with percentage values displayed. For GMRs higher than 1.00 we used the reciprocal value, so that the scale would be symmetrical for comparison.

The maximum deviation from 1.00 of $\mathrm{AUC}_{0-\mathrm{t}}$ and $\mathrm{C}_{\max }$ GMRs was indexed based on the limits of the $90 \%$ CI. For upper limits higher than 1.00 the reciprocal value was used for the reasons already mentioned. Thus, values above $20 \%$ have not appeared in the graphs, even if the upper limit of the CI was 1.25. The maximum differences were arranged by AED in ranges of $5 \%$. We also determined the number of studies for which the $90 \%$ 
CI included 1.00 (i.e. the point where the two products are identical to one another). $\mathrm{CV}$ values were extracted from the reports and graphically presented in ranges of $10 \%$ for each AED.

\section{Bioequivalence estimation for $90 \%$ CI of 0.90 - 1.11}

For some regulatory agencies, the $90 \% \mathrm{CI}$ is tightened to $0.90-1.11$ for narrow therapeutic index (NTI) drugs $(7,19)$ or in case of AEDs (20). We calculated the number of subjects that should be enrolled in each study in order to have enough power $(80 \%)$ for a $90 \% \mathrm{CI}$ of $0.90-1.11$, based on the $\mathrm{CV}$ of $\mathrm{AUC}_{0-\mathrm{t}}$ and $\mathrm{C}_{\max }$. The formula used was (21):

$\mathrm{N}=\left(2 * \mathrm{~S}_{\mathrm{w}}{ }^{2} *\left(\mathrm{Z}_{1-(\beta / 2)}+\mathrm{Z}_{1-\alpha}\right)^{2}\right) /(\ln 1.11)^{2}$

Where, $\mathrm{S}_{\mathrm{w}}{ }^{2}$ is $\ln \left(1+\mathrm{CV}^{2}\right), \mathrm{Z}_{1-(\beta / 2)}$ is the inverse of the two-tailed Student's t-distribution $(0.1)$ for $80 \%$ $1-\beta$, and $Z_{1-\alpha}$ is the inverse of the two-tailed Student's t-distribution $(0.05)$ for $5 \% \alpha$.

The number of subjects considered was the next higher even number of the estimated value; i.e., if $\mathrm{N}$ $=25.3$ we rounded off to 26 , if $\mathrm{N}=26.3$, we considered 28. The studies for which the number of subjects included in the statistical analysis was equal or higher than the considered value, we judged to be adequate. Among them, we identified those with $90 \% \mathrm{CI}$ interval between 0.9 and 1.11 .

\section{Relationship of CV and number of subjects versus accuracy of NTI and non-NTI drugs}

Correlation was investigated between $\mathrm{CV}$ and number of subjects of the studies versus maximum deviations of the PK parameters to evaluate how those variables affected the CI for NTI and non-NTI AEDs and if any constraint could be applied to them. The relationship was graphically illustrated and determined by calculating the Pearson correlation coefficient (r). Based on a list provided by Anvisa, the following were considered NTI drugs: carbamazepine, divalproex, phenytoin and oxcarbazepine (22).

\section{RESULTS}

Data of interest were accessible for 60 approved BE studies of AEDs, corresponding to 10 different substances and 58 formulations. Out of those, 55 were immediate drug release products, two prolonged drug release products (one carbamazepine and one divalproex), and one delayed drug release product (divalproex). The majority was solid oral formulations, only three were oral suspensions. Almost $60 \%$ of these products were manufactured in Brazil.

Only two studies were performed under fed conditions. All enrolled healthy volunteers. About $63 \%$ of confinements were conducted in Brazil and the others in India. Detailed demographic data were not provided in the assessment reports.

\section{Bioequivalence evaluation}

The GMR ranges and mean percent difference in geometric means for $\mathrm{C}_{\max }$ and for $\mathrm{AUC}_{0-\mathrm{t}}$ are shown in Table 1. The highest difference for $\mathrm{AUC}_{0-\mathrm{t}}$ was $9.14 \%$ (lamotrigine); for $83 \%$ of studies the difference was below $5 \%$. For $\mathrm{C}_{\max }, 15 \%$ of studies had difference greater than $10 \%$ up to $13.14 \%$.

$90 \%$ CIs were also evaluated to see how much they deviated from 1.00. In $73.3 \%$ of $\mathrm{BE}$ studies $\mathrm{C}_{\max }$ CI deviated $\leq 15 \%$ and in $40 \%$ of studies, $\leq 10 \%$. For $\mathrm{AUC}_{0-\mathrm{t}}$ the deviation from 1.00 was $\leq 10 \%$ in $75 \%$ of BE studies and $\leq 15 \%$ in $91.7 \%$ of studies (Figure 1). The $\mathrm{CIs}_{\text {for }} \mathrm{C}_{\max }$ and $\mathrm{AUC}_{0-\mathrm{t}}$ were 1.00 in $66.7 \%$ and in $85 \%$ of studies, respectively. The CV of the BE parameters of each study are plotted in Figure 2. Again the $\mathrm{CV}$ is in general higher for $\mathrm{C}_{\max }$ than for $\mathrm{AUC}_{0-\mathrm{t}}$. For some substances such as carbamazepine, clonazepam, divalproex and oxcarbazepine the CV fluctuated from the $0-10 \%$ range to the $>30 \%$-range, indicating inconsistent variability.

\section{Bioequivalence estimation for $90 \%$ CI of 0.90 - 1.11}

Considering the $\mathrm{CV}$ of $\mathrm{AUC}_{0-\mathrm{t}}$ obtained in each BE study, 37 studies used adequate number of subjects for that interval. Among the 36 products that they represent, only one (carbamazepine) had $\mathrm{AUC}_{0}$ $t$ out of the interval, with an upper interval limit of 1.12. All products of clonazepam, phenobarbital, pregabalin and topiramate fit the tighter interval. Drugs for which the studies have not enrolled enough number of subjects and presented CIs beyond the 0.9-1.11 limits for $\mathrm{AUC}_{0-\mathrm{t}}$ are carbamazepine, divalproex, gabapentine, lamotrigine, oxcarbazepine and phenytoin. Studies in which the number of subjects was adequate for both $\mathrm{AUC}_{0-\mathrm{t}}$ e $\mathrm{C}_{\max }$ summed 18. For six of them the CI of $\mathrm{C}_{\max }$ was out of $0.90-1.11$, referring to products of carbamazepine, phenytoin, lamotrigine and oxcarbazepine 
Table 1. Geometric Mean Ratio Ranges and Percent Differences in Geometric Means of Bioequivalence Parameters obtained in Bioequivalence Studies of AED products.

\begin{tabular}{lcc} 
Parameter & Geometric Mean Ratio Range & Mean Difference (\%) \\
$\mathrm{C}_{\mathrm{MAX}}$ & $0.87-1.14$ & $4.84 \pm 3.73$ \\
$\mathrm{AUC}_{0-\mathrm{t}}$ & $0.91-1.10$ & $3.02 \pm 2.10$ \\
\hline
\end{tabular}

${ }^{\mathrm{a}} \mathrm{Mean} \pm \mathrm{SD}$
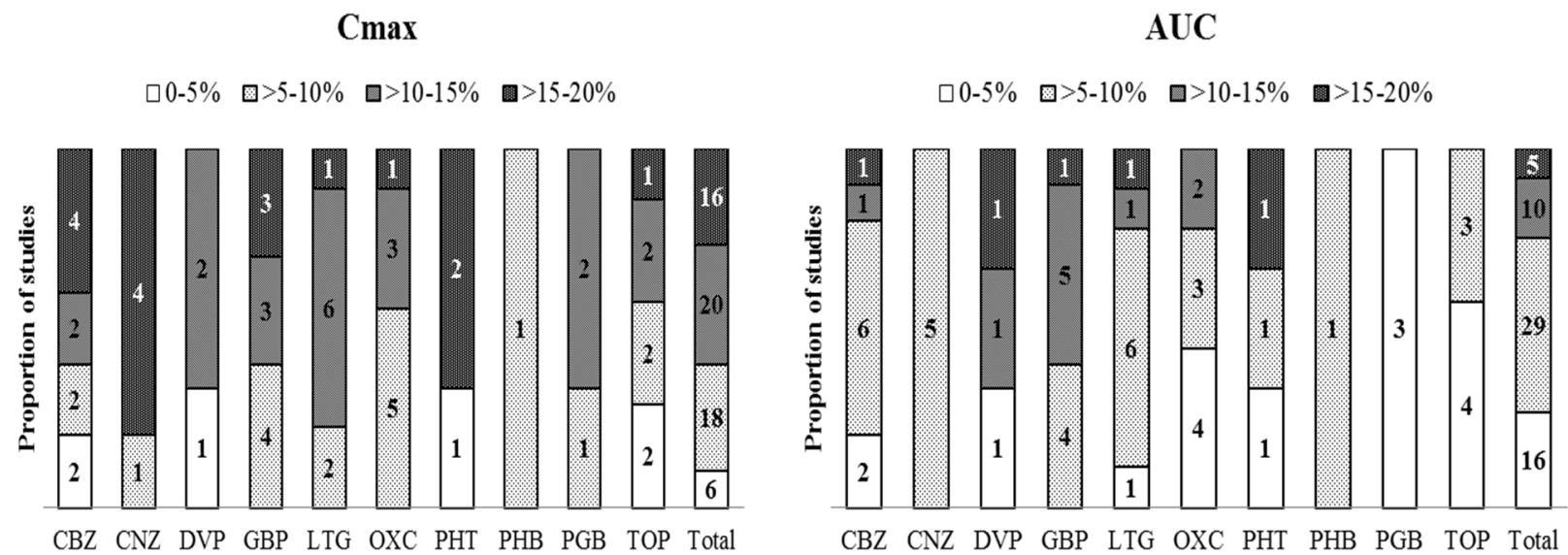

Figure 1. Maximum deviation of the $90 \% \mathrm{CI}$ of $\mathrm{C}_{\max }$ and $\mathrm{AUC}_{0-\mathrm{t}}$ from $\mathrm{BE}$ studies approved by ANVISA. Results are arranged by drug in ranges of $5 \%$. Number of studies within the range are indicated in the columns. Drug abbreviations: $\mathrm{CBZ}=$ Carbamazepine; $\mathrm{CNZ}=$ Clonazepam; $\mathrm{DVP}=$ Divalproex $\mathrm{GBP}=$ Gabapentin $=$ LTG: Lamotrigine; $\mathrm{OXC}=$ Oxcarbazepine; $\mathrm{PHT}=$ Phenytoin PHB $=$ Phenobarbital; $\mathrm{PGB}=$ Pregabalin; $\mathrm{TOP}=$ Topiramate.

$\operatorname{Cmax}$

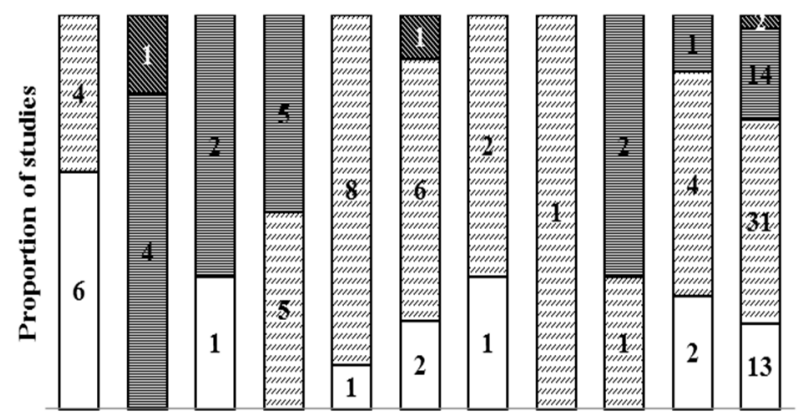

CBZ CNZ DVP GBP LTG OXC PHT PHB PGB TOP Total

口 $>0-10 \%$ 四>10-20\% 目>20-30\% $\mathbb{\mathbb { a }}>30 \%$
AUC

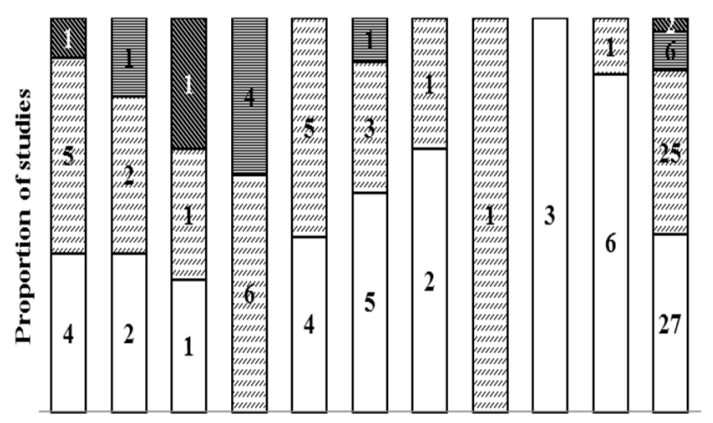

CBZ CNZ DVP GBP LTG OXC PHT PHB PGB TOP Total

$\square 0-10 \%$ 미 $>10-20 \%$ 目 $>20-30 \% \quad \mathbb{\mathbb { S }}>30 \%$

Figure 2. $\mathrm{CV}$ of $\mathrm{C}_{\max }$ and $\mathrm{AUC}_{0-\mathrm{t}}$ from $\mathrm{BE}$ studies approved by Anvisa. Results are arranged by drug in ranges of $10 \%$. Number of studies within the range are indicated in the columns. Drug abbreviations: See Figure 1.

\section{Relationship of $\mathrm{CV}$ and number of subjects versus accuracy of NTI and non-NTI drugs}

Figures 3 and 4 show that for NTI as well as for nonNTI AED there was a strong correlation between the maximum deviation of $\mathrm{CI}$ versus the $\mathrm{CV}$ for $\mathrm{AUC}_{0-\mathrm{t}}$, but for $\mathrm{C}_{\max }$ the correlation was weaker, especially for NTI drugs. For $\mathrm{C}_{\max }$, the $\mathrm{CV}$ values were mainly between 10 and $30 \%$ for non-NTI drug studies and between 5 and 20\% for NTI drug studies, indicating more intra-subject variability in the absorption rate of non-NTI drug products. This would certainly reflect on the maximum deviation of CI, which was above $10 \%$ for almost $63 \%$ of non-NTI drugs and $56 \%$ of NTI drug studies. It was also observed that CV higher than $20 \%$ always led to deviations higher than $10 \%$. 
For $\mathrm{AUC}_{0-\mathrm{t}}$, almost $23 \%$ of non-NTI and $28 \%$ of NTI drug studies presented CI with maximum deviation of $\mathrm{AUC}_{0-\mathrm{t}}>10 \%$. The trend line equations (Figure 4) show that when the maximum deviation is $10 \%$, the $\mathrm{CV}$ is nearly $15 \%$. Approximately $71 \%$ of non-NTI drug studies and $72 \%$ of NTI drug studies presented $\mathrm{CV}$ of $\leq 15 \%$ for $\mathrm{AUC}_{0-\mathrm{t}}$,
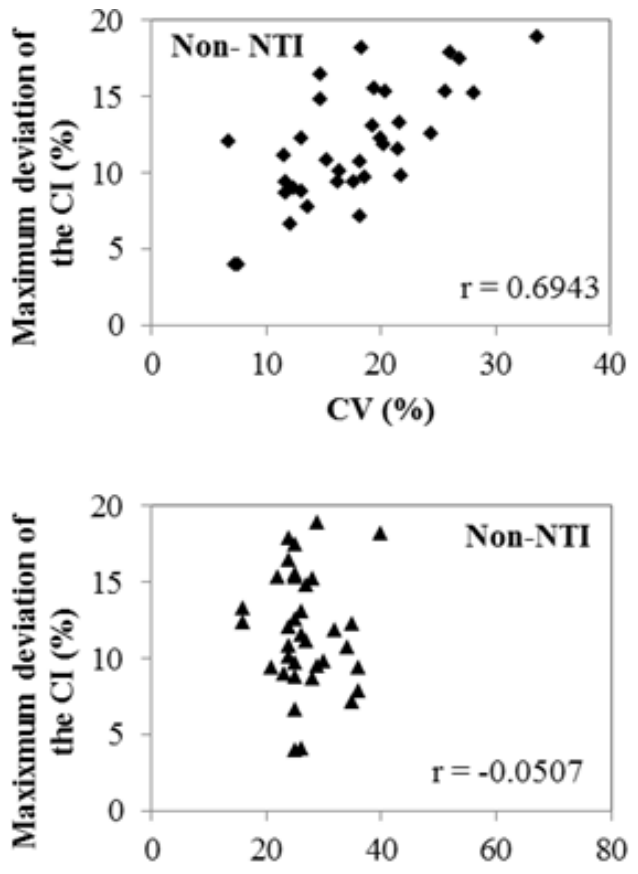

Number of Subjects comprising all drug substances. Approximately $66 \%$ of non-NTI drug studies and $64 \%$ of NTI drug studies presented maximum deviation of the $\mathrm{CI} \leq$ $10 \%$ together with $\mathrm{CV} \leq 15 \%$ for $\mathrm{AUC}_{0-\text { t. }}$. Although very small, there was a tendency for negative correlation between maximum deviation and number of subjects enrolled in the BE studies.
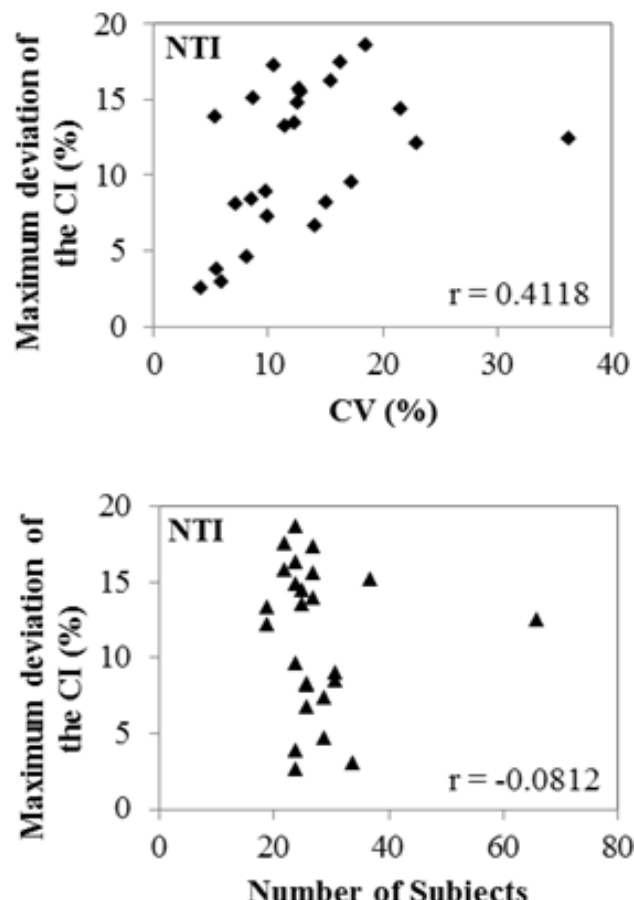

Figure 3. Maximum Deviation of the $90 \% \mathrm{CI}$ of $\mathrm{C}_{\max }$ and Their Correlation with $\mathrm{CV}$ and Number of Subjects for Non-NTI and NTI AEDs .
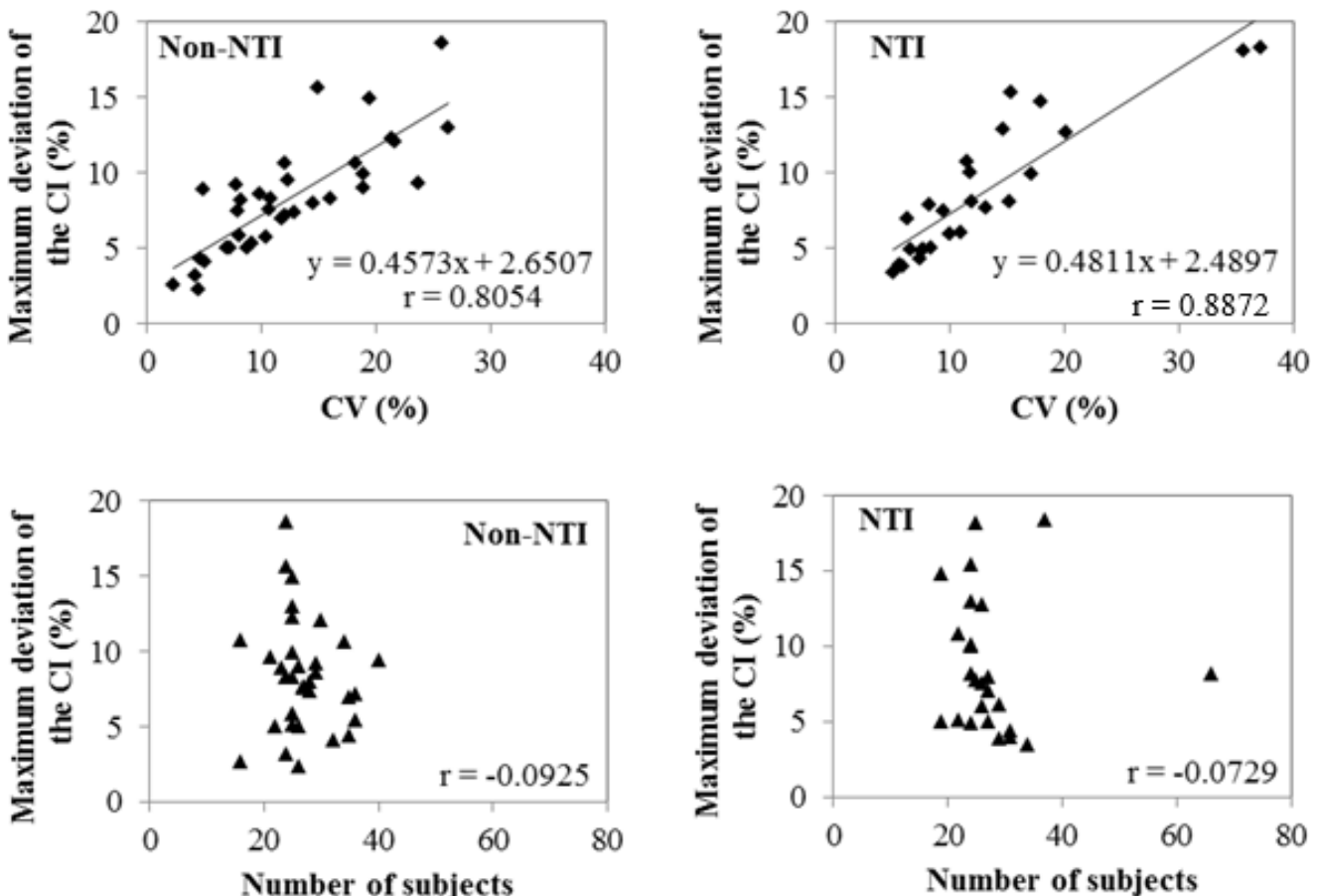

Figure 4. Maximum Deviation of the $90 \%$ CI of $\mathrm{AUC}_{0-\mathrm{t}}$ and Their Correlation with CV and Number of Subjects for NonNTI and NTI AEDs. 


\section{DISCUSSION}

Although the number of BE studies of AED products with available assessment reports was small compared to other similar published surveys, when we look at the GMRs of $\mathrm{C}_{\max }$ and $\mathrm{AUC}_{0-\mathrm{t}}$ we see that our results are comparable to the others, in which generic and reference drug products were considered very similar (23-25). GMR, however, indicates the formulation performance in a sample of subjects. In $\mathrm{BE}$ studies, the target is the real mean ratio, since that $\mathrm{BE}$ result will be extrapolated to the whole population. For that, a CI is calculated, which is likely to contain the true population parameter (26, 27). When we compare our CI data to those of Krauss and co-workers, we observe that they found better results when they evaluated 258 AED BE studies approved by FDA (28). In their data set, mean $\mathrm{AUC}_{0 \text {-t }}$ values differed by $<10 \%$ in $83 \%$ and $<15 \%$ in $98.8 \%$ of $\mathrm{BE}$ studies and $\mathrm{C}_{\max }$ by 15 to $25 \%$ in $11 \%$ of studies. It is important to mention that in that study, the reciprocal values of GMRs higher than 1.00 were not used for deviation measurement. Hence values as high as $25 \%$ appear in the survey. For comparison, when we used the same calculation method as in Krauss et al., our results were $71.7 \%$ of BE studies with maximum difference of $\leq 10 \%$ and $91.7 \%$ of BE studies with $\mathrm{AUC}_{0-\mathrm{t}}$ of $\leq 15 \%$. For $\mathrm{C}_{\max }$ the result would have been $28.3 \%$ of BE studies with maximum difference of $15-25 \%$. It is well-known that $\mathrm{C}_{\max }$ is a much variable parameter, since it is a single point estimation that depends, among other things on the time of sampling.

Drug characteristics, such as low oral bioavailability and extensive first pass metabolism, certainly play a role in the variability of product performance in vivo (29). However it was noted that among studies of the same drug substance, differences $>10 \%$ in $\mathrm{AUC}_{0-\mathrm{t}}$ were minority (except for divalproex and gabapentin), indicating more of a product performance issue than of a drug matter per se. Indeed, when we look at the CVs of the studies we see inconsistent variability for some drug substances, which means that they were highly variable in some $\mathrm{BE}$ studies $(\mathrm{CV}>30 \%)$ but not in others (29).

As already mentioned, the limits of the regular BE CI (0.80-1.25) in the bioavailability of generic and reference AEDs is controversial. In Denmark, generic formulations of AEDs (except for levetiracetam and benzodiazepines) must meet the $90 \%$ CI of $90-111 \%$ for $C_{\max }$ and AUC (20). The European Medicines Agency and the Health Canada advocates that the CI of AUC should be tightened to
$0.90-1.11$ and to $0.90-1.12$, respectively, only for NTI drugs $(7,19)$, assuming that $10 \%$ or lower variation in PK would not lead to a clinically relevant difference. The FDA has been discussing the application of scaled average BE approach for NTI drugs, in which the $90 \% \mathrm{CI}$ is tightened based on the $\mathrm{CV}$ of the reference product, with BE limits of 0.80 1.25 for CV higher than $21.42 \%(11,30)$. If we take a look at our results, $75 \%$ of studies would fit the interval 0.90-1.11 for $\mathrm{AUC}_{0-\mathrm{t}}$ and only $35 \%$ would fit it for both $\mathrm{AUC}_{0-\mathrm{t}}$ and $\mathrm{C}_{\max }$. One could argue, though, that the number of subjects enrolled would have not given enough power to a tighter interval. Considering just the studies that used sufficient number of subjects to conclude $\mathrm{BE}$ in the $90 \% \mathrm{CI}$ of 0.90-1.11 for $\mathrm{AUC}_{0-\mathrm{t}}$, only one was out of the interval, with an upper interval limit of 1.12 for carbamazepine. Therefore, all of them would have met the Canadian criteria. If a more restrictive criterion is applied, such as that of the Danish authority, according to which both $\mathrm{AUC}_{0-\mathrm{t}}$ and $\mathrm{C}_{\max }$ have to meet that interval, one third of studies that enrolled sufficient number of individuals would not demonstrate BE.

Even though we showed that in general the differences between generic medicines and their reference products approved by the Brazilian regulatory agency are small, it raises attention that six products of carbamazepine, divalproex (prolonged release), oxcarbazepine and phenytoin (corresponding to $24 \%$ of studies of NTI AEDs) were approved with differences that could be higher than $10 \%$ in the population (CI exceeded the limits of 0.90-1.11 for $\mathrm{AUC}_{0-\mathrm{t}}$ ). If adequate number of subjects to a tighter interval had been used in those studies, we would have a more precise scenario regarding the similarity of those AEDs.

It is reasonable to assume that fluctuations in plasma levels of AEDs could cause seizure/adverse effect in an otherwise controlled patient. Although such fluctuation can have a number of sources, one that particularly interests regulatory agencies is the quality of AED products available in the market/public health system. Therefore the question is, how much fluctuation is tolerable and how can this be controlled in terms of drug-product quality? So far, there are no studies in the literature to indicate precisely the level of fluctuation that will produce seizure/adverse effect. Thus the only alternative is to keep the fluctuation to a minimum. To this end, we believe that the safety of a switch between drug products should be also evaluated in terms of drug product performance variance within a given subject, by controlling the $\mathrm{CV}$. 
We showed that the $\mathrm{CV}$ values contributed strongly to the maximum deviation of $\mathrm{CI}$ of $\mathrm{AUC}_{0-\mathrm{t}}$, either for non-NTI or for NTI drugs. Because $\mathrm{C}_{\max }$ is a very variable parameter, the correlation between $\mathrm{CV}$ and maximum deviation was weaker, but still significant. Surprisingly, no correlation was seen between the number of subjects enrolled in the studies and the maximum difference of a PK parameter in population. We think that the number of subjects used in each study was not considerably different to show any effect on the CI amplitude, but there was a tendency for a negative correlation, as expected.

Based strictly on the PK data presented in this survey, it seems that the regular BE CI criterion of $0.80-1.25$ is too wide for the investigated AEDs. It would be conceivable to set the $90 \% \mathrm{CI}$ of $\mathrm{AUC}_{0-\mathrm{t}}$ within 0.90-1.11, for both NTI and non-NTI AEDs, because the majority of studies complied with that interval and all substances investigated had products with maximum difference $\leq 10 \%$. Being more restrictive, the $\mathrm{CV}$ value for those drug products could be limited to $15 \%$, which is approximately the $\mathrm{CV}$ obtained when the estimated maximum deviation is $10 \%$, to avoid discrepancies in the variability of reference and generic formulations. Exceptions could be made for drug products whose references present intra-subject variability higher than $15 \%$, and in those cases the CV value could be limited to not more than the $\mathrm{CV}$ of reference versus reference comparison. Considering the 60 studies evaluated here, $65 \%$ (comprising all drug substances) would comply with these requirements. The advantage of this proposal is that, by limiting the $\mathrm{CV}$, we may be able to eliminate concerns about overpowered BE studies, where an exceeding number of subjects are enrolled in order to reach the required CI, because the CI would not be the only target to be achieved. In addition, replicate design studies would be needed only when there was a suspicion that the $\mathrm{CV}$ of the reference formulation was higher than $15 \%$ and not for every BE study as it is the case when scaled average BE approach is applied.

Those constraints, however, would not apply to $\mathrm{C}_{\max }$, since the majority of studies presented maximum deviations higher than $10 \%$ and a weaker correlation was seen between CV and the maximum deviation. Even though trend lines were to be traced in Figure 3, they would show that for NTI drugs the $\mathrm{CV}$ had to be nearly $9 \%$ in order to obtain a maximum deviation of $10 \%$, which is a very low value if we consider that the precision of bioanalytical methods is allowed to be up to $15 \%$.
Thus, any further limitation imposed to $\mathrm{C}_{\max }$, without a known reason, could be too restrictive.

Finally, it is premature to suggest that the treatment failure reported by Guilhoto and coworkers (2009) is a result of differences larger than $10 \%$ in PK parameters and/or due to high variability of formulations, since other factors such as lack of treatment adherence and "nocebo" effect could have contributed as well. Further, it was not clear in their report if the switch was between reference and generic formulations or between generics; in the last case the difference in PK parameters after substitution can be much larger especially if the CI observed in the BE studies of the two generic formulations were shifted toward opposite BE limits.

\section{CONCLUSIONS}

In conclusion, our data indicate that generic and reference AED products registered in Brazil can be equally effective. Some products containing NTI drugs presented differences in AUC considered to be too high in other countries (i.e., $>10 \%$ ); for this reason we advise careful monitoring of patients when switching between formulations of carbamazepine, divalproex, oxcarbazepine and phenytoin. We also showed that constraining the $\mathrm{AUC}_{0-\mathrm{t}} 90 \% \mathrm{CI}$ to $0.90-1.11$ and also limiting the CV to $15 \%$ in BE studies of AEDs is technically and commercially feasible since most AED products already adhere to the proposed requirements. Although we cannot state that such restrictions are necessary to guarantee treatment success, we believe that more restrictive regulations would enhance public confidence in product substitution once they would potentially improve the assurance that drug products deemed "bioequivalent" are indeed therapeutically equivalent and therefore interchangeable.

\section{Disclosure of Conflicts of Interest}

None of the authors has any conflict of interest to disclose. This article reflects the scientific opinion of the authors and not necessarily the policies of the regulatory agency.

\section{REFERENCES}

1. Ivanez V. The concept and treatment of drug-resistant intractable epilepsy. Rev Neurol, 1995; 23(124):1214-9.

2. Shaw SJ, Hartman AL. The Controversy over Generic Antiepileptic Drugs. J Pediatr Pharmacol Ther 2010; 15(2):81-93. 
3. Miranda ES, Pinto CBS, Reis ALA, et al. Availability of generic drugs in the public sector and prices in the private sector in different regions of Brazil. Cad Saude Publica, 2009; 25(10):2147-58.

4. Gagne JJ, Avorn J, Shrank WH, Schneeweiss S. Refilling and switching of antiepileptic drugs and seizure-related events. Clin Pharmacol Ther, 2010; 88(3):347-53.

5. Steinhoff BJ, Runge U, Witte OW, et al. Substitution of anticonvulsant drugs. Ther Clin Risk Manag, 2009; 5(3):449-57.

6. Brazilian Ministry of Health - Agência Nacional de Vigilância Sanitária (ANVISA). Resolução RE $\mathrm{n}^{\circ}$ 1.170, de 19 de abril de 2006. Anexo - Guia para provas de biodisponibilidade relativa/bioequivalência de medicamentos, 2006. http://www.in.gov.br/visualiza/index.jsp?jornal=1\& pagina $=101 \&$ data $=24 / 04 / 2006$ Accessed: September 9, 2013.

7. European Medicines Agency (EMA). Guideline on the investigation of bioequivalence, 2010. http://www.emea.europa.eu/docs/en_GB/document library/Scientific_guideline/2010/01/WC500070039. pdf Accessed: September 9, 2013.

8. U.S. Food and Drug Administration (FDA). Guidance for Industry: Bioavailability and Bioequivalence Studies for Orally Administered Drug Products - General Considerations, 2003. http://www.fda.gov/downloads/Drugs/.../Guidances/ ucm070124.pdf3. Accessed: September 9, 2013.

9. Schuirmann DJ. A comparison of the two one-sided tests procedure and the power approach for assessing the equivalence of average bioavailability. J Pharmacokinet Biopharm, 1987; 15(6):657-80.

10. U.S. Food and Drug Administration (FDA). Approved Drug Products with Therapeutic Equivalence Evaluations, 2012.

http://www.fda.gov/Drugs/DevelopmentApprovalPr ocess/ucm079068\#. Accessed: September 9, 2013.

11. Bialer M, Midha KK. Generic products of antiepileptic drugs: a perspective on bioequivalence and interchangeability. Epilepsia, 2010; 51(6):94150.

12. Privitera MD. Generic antiepileptic drugs: current controversies and future directions. Epilepsy Curr, 2008; 8(5):113-7.

13. LeLorier J, Duh MS, Paradis PE, et al. The risks of multiple-generic substitution of antiepileptic drugs: the case of topiramate. Poster \#PND46 presented at ISPOR 13th Annual International Meeting; Toronto, ON, Canada 2008. http://www.ispor.org/awards/13meet/presentations/P ND46.pdf Accessed: September 9, 2013.

14. LeLorier J, Duh MS, Paradis PE, et al. Clinical consequences of generic substitution of lamotrigine for patients with epilepsy. Neurology, 2008; 70(22 Pt 2):2179-86.

15. Andermann F, Duh MS, Gosselin A, Paradis PE. Compulsory generic switching of antiepileptic drugs: high switchback rates to branded compounds compared with other drug classes. Epilepsia, 2007; 48(3):464-9. Epub 2007/03/10.

16. Crawford P, Feely M, Guberman A, Kramer G. Are there potential problems with generic substitution of antiepileptic drugs? A review of issues. Seizure, 2006; 15(3):165-76.

17. Bautista RE, Gonzales W, Jain D. Factors associated with poor seizure control and increased side effects after switching to generic antiepileptic drugs. Epilepsy Res, 2011; 95(1-2):158-67.

18. Guilhoto LMFF, Alexandre V, Martins HH, et al. Há riscos na utilização de diferentes formulações de drogas antiepilépticas? Relato da ABE através de entrevista de pessoas com epilepsia. Journal of Epilepsy and Clinical Neurophysiology, 2009; 15:419.

19. Health Canada. Guidance Document - Comparative Bioavailability Standards: Formulations Used for Systemic Effects, 2012. http://www.hc-sc.gc.ca/dhpmps/alt_formats/pdf/prodpharma/applic-

demande/guide-ld/bio/gd_standards_ld_normeseng.pdf Accessed: September 9, 2013.

20. Danish Health and Medicines Authority (DKMA). Bioequivalence and labelling of medicines with regard to generic substitution, 2012.

http://www.dkma.dk/en/topics/authorisation-andsupervision/licensing-of-medicines/marketingauthorisation/application-for-marketingauthorisation/bioequivalence-and-labelling-ofmedicine--bstitution Accessed: September 9, 2013.

21. Julious SA. Sample sizes for clinical trials with normal data. Stat Med, 2004; 23(12):1921-86.

22. Brazilian Ministry of Health - Agência Nacional de Vigilância Sanitária (ANVISA). Resolução RDC no 67, de 08 de outubro de 2007. Anexo II - Boas práticas de manipulação de substâncias de baixo índice terapêutico, 2007.

http://www.anvisa.gov.br/hotsite/segurancadopacie nte/documentos/rdes/RDC\%20N\%C2\%BA\%20672007.pdf Accessed: September 9, 2013.

23. Davit BM, Nwakama PE, Buehler GJ, et al. Comparing generic and innovator drugs: a review of 12 years of bioequivalence data from the United States Food and Drug Administration. Ann Pharmacother, 2009; 43(10):1583-97.

24. Henney JE. Review of generic bioequivalence studies. JAMA, 1999; 282(21):1995.

25. Nightingale SL, Morrison JC. Generic drugs and the prescribing physician. JAMA, 1987; 258(9):1200-4.

26. Patterson, S.; Jones, B., Bioequivalence and Statistics in Clinical Pharmacology. CRC, Boca Raton, FL, USA, 2006.

27. Chow, S-C.; Liu, J-P., Design and Analysis of Bioavailability and Bioequivalence Studies. 3rd ed., CRC, Boca Raton, FL, USA, 2009.

28. Krauss GL, Caffo B, Chang YT, Hendrix CW, Chuang K. Assessing bioequivalence of generic antiepilepsy drugs. Ann Neurol, 2011; 70(2):221-8.

29. Davit BM, Conner DP, Fabian-Fritsch B, et al. Highly variable drugs: observations from bioequivalence 
data submitted to the FDA for new generic drug applications. AAPS J, 2008; 10(1):148-56.

30. Endrenyi L, Tothfalusi L. Determination of Bioequivalence for Drugs with Narrow Therapeutic
Index: Reduction of the Regulatory Burden. J Pharm Pharm Sci, 2013; 16(5):676-82. 